\title{
Preliminary study of lateral variation in crustal structure of Northeast China from teleseismic receiver functions*
}

\author{
Youlin Chen ${ }^{1, \uparrow}$ Ruifeng Liu ${ }^{2}$ Zhibin Huang ${ }^{2}$ and Li Sun ${ }^{2}$ \\ ${ }^{1}$ Array Information Technology, Maryland 20770, USA \\ ${ }^{2}$ China Earthquake Networks Center, Beijing 100045, China
}

\begin{abstract}
We conducted comprehensive receiver function analyses for a large amount of high-quality broadband teleseismic waveforms data recorded at 19 China National Digital Seismic Network (CNDSN) stations deployed in Northeast China. An advanced $H-\kappa$ domain search method was adopted to accurately estimate the crustal thickness and $v_{\mathrm{P}} / v_{\mathrm{S}}$ ratio. The crust has an average thickness of about $34.4 \mathrm{~km}$. The thinnest crust occurs in the central region of Northeast China, while the thickest crust is beneath the Yanshan belt. The $v_{\mathrm{P}} / v_{\mathrm{S}}$ ratio is relatively uniform with an average of about 1.733 . The highest $v_{\mathrm{P}} / v_{\mathrm{S}}$ ratio is found beneath the Changbaishan, likely associated with its volcanic activities. We found significant lateral heterogeneity beneath three stations CN2, MDJ, and MIH located along the Suolon suture from the back-zimuthal dependence of Moho depth. The velocity modeling from receiver functions indicated complicated Earth structure beneath these stations with large crust-mantle transition zone, noticeable velocity jump in upper mantle, and low velocity zone in middle crust. Dipping velocity interface in the crust with strike approximately parallel to the Suolon suture and down-dip to the south or southeast might explain the observed lateral heterogeneity.
\end{abstract}

Key words: Moho; crust; receiver function; lateral heterogeneity

CLC number: P315.2 Document code: A

\section{Introduction}

Northeast China consists of tectonic collages of accreted late Paleozoic terranes, which include a series of fold belts and sedimentary basins. It is delimited to the south by the Permo-Triassic Suolon suture and to the north by the Cretaceous Mongolo-Okhotsk suture (Figure 1). Northeast China is comprised of part of the Sino-Korean Craton and part of the Mongolian accretionary fold belt. During the late Permian and early Triassic, the Mongolian arc terrane was finally welded together with Sino-Korean Craton along the Suolon suture (Yin and Nie, 1996; Davis et al., 2001; Graham et al., 2001). The Suolon suture was reactivated of its southern part in the Mesozoic to form the Yanshan

\footnotetext{
* Received 9 October 2010; accepted in revised form 1 January 2011; published 10 February 2011.

^ Corresponding author. e-mail: youlinchen01@gmail.com

(C) The Seismological Society of China and Springer-Verlag Berlin Heidelberg 2011
}

fold belt. During the same geologic period, large sedimentary Basins, such as the Hailar and Songliao Basins, formed. This region was also influenced by the important subduction processes during most of its history of evolution, such as the Mongolo-Okhotsk ocean subduction to the both north and south during the late Triassic (Vermeesch, 2003).

The importance of the evolutionary history of Northeast China results in relatively complicated crustal and upper mantle structure beneath this region. As a preliminary result, we studied lateral heterogeneity of the crust by applying teleseismic receiver function technique on the China National Digital Seismic Network (CNDSN) deployed in Northeast China in this paper. Since the later 1990s, the China Earthquake Administration (CEA) has spent tremendous efforts on building modern digital seismic networks. The CNDSN has been accumulating a large amount of high-quality waveform data applied in all sorts of geophysical studies for China (e.g., Huang et al., 2003; Ma and Zhou, 
2007; Zheng et al., 2008). Chen et al. (2010) measured the crustal thickness (defined as Moho depth), and average crustal $v_{\mathrm{P}} / v_{\mathrm{S}}$ ratio (also the better known crustal elastic property Poisson's ratio) through a comprehensive receiver function analysis on teleseismic waveforms recorded at 48 first-order CNDSN stations to investigate the crustal structure and properties across China. The receiver function models provided complementary constraints for the Earth structure and properties from independent perspective comparable to other geophysical models derived from travel-time tomography and deep seismic sounding (DSS) experiments conducted across China (e.g., Cui et al., 1995; Li and Mooney, 1998; Wang et al., 2000; Vergne et al., 2002; Wang et al., 2003, 2007; Liang et al., 2004; Pei et al., 2004; Sun et al., 2004;
Zhang et al., 2005; Sun and Toksöz, 2006; Li et al., 2006; Liu et al., 2006; Zhao et al., 2006; Sun et al., 2008). In this study, we performed comprehensive receiver function analyses on nine first-order CNDSN stations and ten regional stations deployed in the region of Northeast China (Figure 1). All first-order stations were collected more than 230 receiver function traces with high quality, while most regional stations had 70-110 receiver function traces. The ample number of recordings enables excellent back-azimuthal coverage of each station. We first measure the crustal thickness and $v_{\mathrm{P}} / v_{\mathrm{S}}$ ratio beneath each statoin, and then investigate the possible lateral variations of the crustal structure from the variation of the receiver functions dependent on back azimuths.

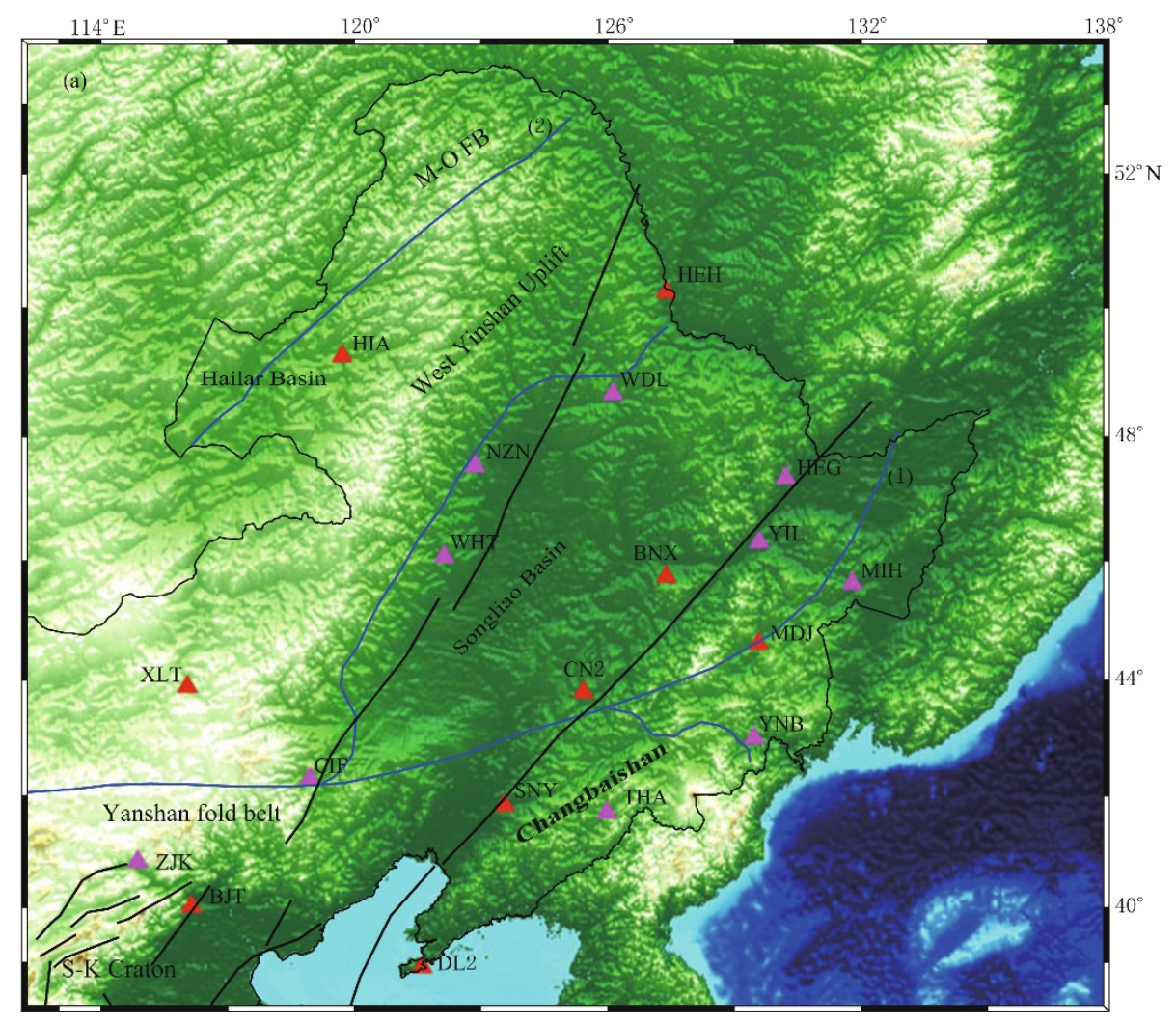

Figure 1 Distribution of 19 CNDSN stations (triangles) used in this study. The red triangles represent the first-order CNDSN stations, while the magenta triangles represent the regional stations. The topographic map also shows major tectonic blocks and faults in this region. Abbreviations on the map are Mongol-Okhotsk fold belt (M-O FB); Sino-Korean Craton (S-K Craton); Suolon suture (1); Mongolo-Okhotsk suture (2).

\section{Measurements for crustal thick-} ness and $v_{\mathrm{P}} / v_{\mathrm{S}}$ ratio

The information of Earth's structure near the receiver site contained in teleseismic $\mathrm{P}$-waveforms can be isolated by deconvolving the vertical from the horizontal components to remove the source and distant path effects, which are in common in both vertical and horizontal components (e.g., Langston, 1979; Ammon, 1991). The resultant receiver function is most sensi- 
tive to the velocity discontinuities beneath the recording site that generates P-to-S conversions. Therefore, the receiver function technique provides a stable way to determine the crustal thickness, the $v_{\mathrm{P}} / v_{\mathrm{S}}$ ratio, the density contrast across the Moho, as well as shear-wave velocity structure in the crust and upper mantle.

In this study, we adopted an advanced $H-\kappa$ (crustal thickness $-v_{\mathrm{P}} / v_{\mathrm{S}}$ ratio) domain stacking and search procedure to estimate crustal thickness and $v_{\mathrm{P}} / v_{\mathrm{S}}$ ratio simultaneously. The stacking for amplitudes of the primary P-to-S converted phase and crustal multiples usually results in relatively strong trade-off between $H$ and $\kappa$ (e.g. Nair et al., 2006). We calculated the coherence between P-to-S converted phase and crustal multiples at different $\kappa$ values, and applied their semblance as an additional weighting factor in stacking. This new technique has been proven efficiently to eliminate the trade-off between $H$ and $\kappa$ (refer Niu et al. (2007) and Chen et al. (2010) for details). We utilized teleseismic waveforms coming from all back-azimuthal directions in order to obtain average crustal thickness and $v_{\mathrm{P}} / v_{\mathrm{S}}$ ratio beneath each station.

We show our results on all used stations in Northeast China in Figure 2 and Table 1 . Table 1 also lists the actual number of receiver functions used by each station, measurement errors, as well as comparison with a tomographic model for China (Sun and Toksöz, 2006; Sun et al., 2008) and Crust2.0 model (Bassin et al., 2000). The average crustal $\mathrm{P}$-wave velocity used in $H$ - $\kappa$ stacking is taken from Sun and Toksöz (2006) tomographic model (Table 1). Among the results of these stations, YIL presents a thick crust and very low $v_{\mathrm{P}} / v_{\mathrm{S}}$ ratio. However, considering the fact that it has only eight receiver functions used for computation (Table 1), the measurements on this station are not as reliable as other stations. Excluding YIL, the crustal thickness of this region ranges from $29 \mathrm{~km}$ to $39 \mathrm{~km}$ with an average of $34.4 \mathrm{~km}$, while the $v_{\mathrm{P}} / v_{\mathrm{S}}$ ratio ranges from 1.65 to 1.79 with an average of $1.733(\sigma=0.251)$.

We generate $2 \mathrm{D}$ relief maps for crustal thickness and $v_{\mathrm{P}} / v_{\mathrm{S}}$ ratio (Figure 3 ) by inverting values at meshed grids of $0.5^{\circ} \times 0.5^{\circ}$ from 18 (excluding YIL) reliable
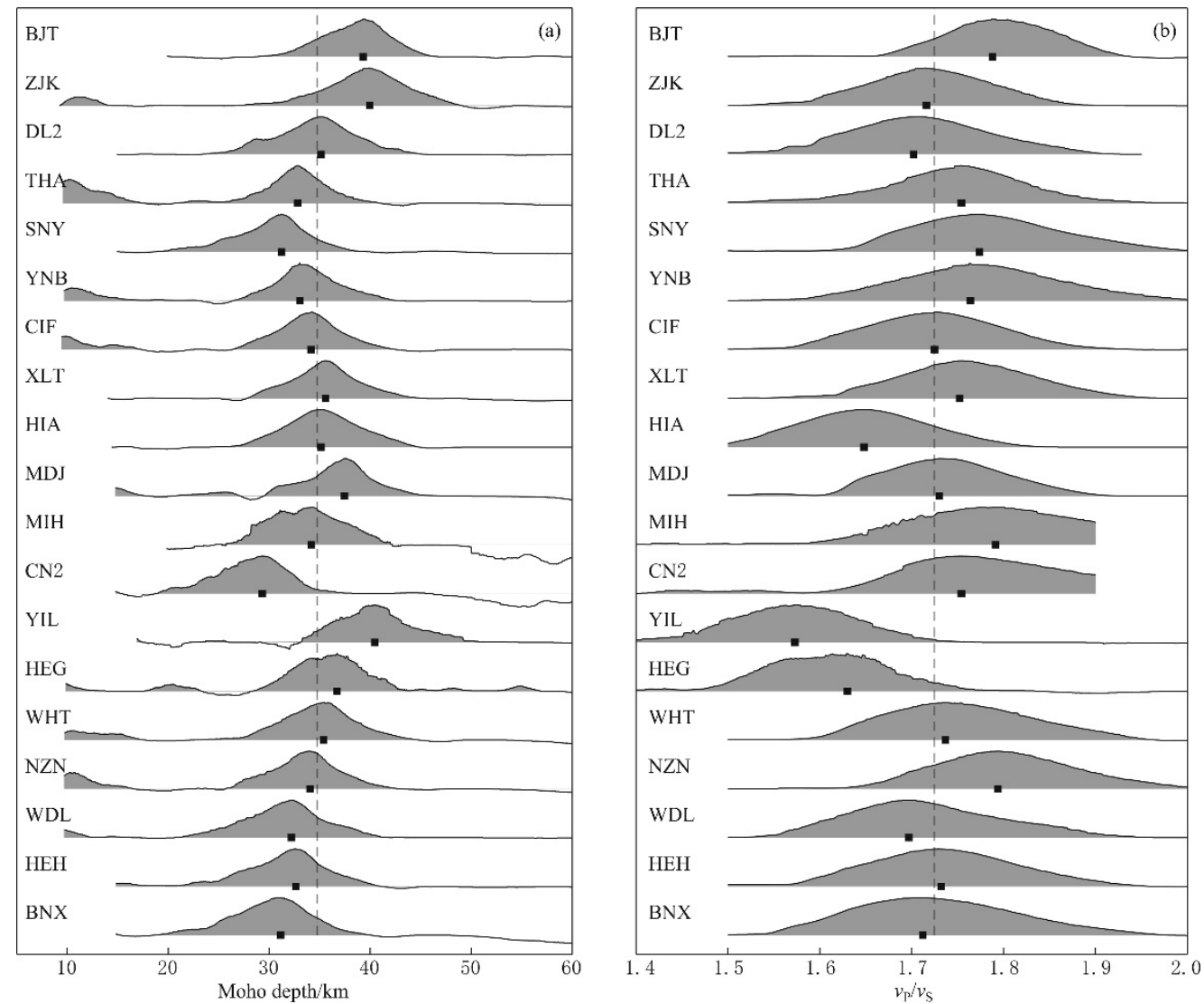

Figure 2 Stacked receiver functions are mapped to depth (a) and to $v_{\mathrm{P}} / v_{\mathrm{S}}$ ratio (b). The squares denote the maximum peak corresponding to the depth of Moho (a) and appropriate crustal $v_{\mathrm{P}} / v_{\mathrm{S}}$ ratio (b). The vertical lines indicate the average values across our study region. 
Table 1 Results of the Moho depth, $v_{\mathrm{P}} / v_{\mathrm{S}}$ ratio, the average crustal $v_{\mathrm{P}}$ used in $H$ - $\kappa$ search, and comparison to tomographic model and Crust2.0

\begin{tabular}{|c|c|c|c|c|c|c|c|c|}
\hline $\begin{array}{l}\text { Station } \\
\text { code }\end{array}$ & $\begin{array}{l}\text { Number } \\
\text { of RFs }\end{array}$ & $\begin{array}{l}\text { Moho depth } \\
\quad / \mathrm{km}\end{array}$ & $v_{\mathrm{P}} / v_{\mathrm{S}}$ & $\begin{array}{c}v_{\mathrm{P}} \\
/\left(\mathrm{km} \cdot \mathrm{s}^{-1}\right)\end{array}$ & $\begin{array}{c}\text { Moho/km } \\
\text { (Tomo) }\end{array}$ & $\begin{array}{c}v_{\mathrm{P}} / v_{\mathrm{S}} \\
\text { (Tomo) }\end{array}$ & $\begin{array}{l}\text { Moho/km } \\
\text { (Crust2.0) }\end{array}$ & $\begin{array}{c}v_{\mathrm{P}} / v_{\mathrm{S}} \\
\text { (Crust2.0) }\end{array}$ \\
\hline BJT & 536 & $39.3 \pm 0.3$ & $1.788 \pm 0.009$ & 6.4799 & 31.0 & 1.77 & 30.0 & 1.78 \\
\hline ZJK & 87 & $40.0 \pm 0.2$ & $1.716 \pm 0.005$ & 6.5080 & 36.6 & 1.76 & 31.0 & 1.76 \\
\hline DL2 & 231 & $35.1 \pm 0.4$ & $1.702 \pm 0.016$ & 6.2400 & 31.8 & 1.80 & 30.0 & 1.81 \\
\hline THA & 73 & $32.8 \pm 0.3$ & $1.754 \pm 0.008$ & 6.4508 & 38.9 & 1.78 & 37.0 & 1.76 \\
\hline SNY & 246 & $31.2 \pm 0.5$ & $1.774 \pm 0.015$ & 6.4194 & 39.3 & 1.75 & 37.0 & 1.76 \\
\hline YNB & 83 & $33.0 \pm 0.1$ & $1.764 \pm 0.003$ & 6.5813 & 39.5 & 1.77 & 32.0 & 1.79 \\
\hline $\mathrm{CIF}$ & 113 & $34.1 \pm 0.2$ & $1.725 \pm 0.003$ & 6.3704 & 33.8 & 1.72 & 31.0 & 1.76 \\
\hline XLT & 277 & $35.6 \pm 0.4$ & $1.752 \pm 0.016$ & 6.2367 & 39.1 & 1.75 & 37.0 & 1.76 \\
\hline HIA & 505 & $35.1 \pm 0.7$ & $1.648 \pm 0.027$ & 6.4010 & 39.0 & 1.80 & 36.5 & 1.78 \\
\hline MDJ & 696 & $37.5 \pm 0.3$ & $1.730 \pm 0.016$ & 6.4514 & 39.5 & 1.78 & 32.0 & 1.79 \\
\hline MIH & 8 & $34.2 \pm 0.4$ & $1.791 \pm 0.014$ & 6.5451 & 38.7 & 1.83 & 37.0 & 1.76 \\
\hline $\mathrm{CN} 2$ & 26 & $29.3 \pm 0.4$ & $1.754 \pm 0.010$ & 6.5453 & 43.2 & 1.88 & 37.0 & 1.76 \\
\hline YIL & 8 & $40.4 \pm 0.3$ & $1.573 \pm 0.007$ & 6.5532 & 38.8 & 1.78 & 37.0 & 1.76 \\
\hline HEG & 110 & $36.7 \pm 0.2$ & $1.630 \pm 0.005$ & 6.5019 & 38.9 & 1.82 & 36.5 & 1.78 \\
\hline WHT & 90 & $35.4 \pm 0.3$ & $1.737 \pm 0.006$ & 6.3270 & 38.7 & 1.73 & 39.0 & 1.77 \\
\hline NZN & 78 & $34.0 \pm 0.4$ & $1.794 \pm 0.015$ & 6.4437 & 39.1 & 1.78 & 37.0 & 1.78 \\
\hline WDL & 99 & $32.2 \pm 0.3$ & $1.697 \pm 0.011$ & 6.4412 & 38.9 & 1.75 & 36.5 & 1.78 \\
\hline HEH & 278 & $32.6 \pm 0.3$ & $1.732 \pm 0.009$ & 6.5361 & 40.7 & 1.84 & 36.5 & 1.78 \\
\hline BNX & 243 & $31.2 \pm 0.3$ & $1.712 \pm 0.015$ & 6.5254 & 39.5 & 1.80 & 37.0 & 1.76 \\
\hline
\end{tabular}
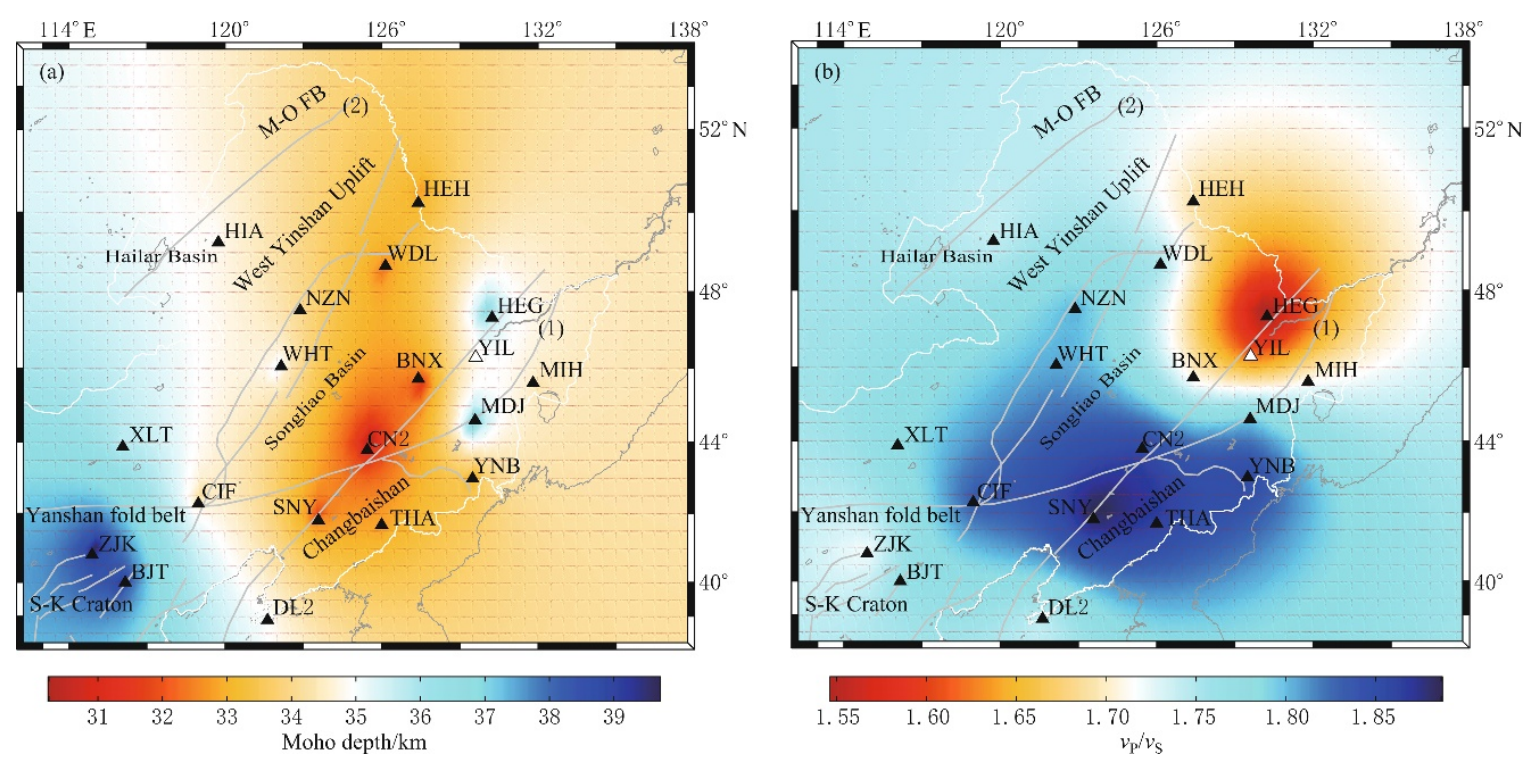

Figure 3 Moho relief map inverted from observations on stations shown as solid triangles. The stations in open triangles are not used for inversion. (b) Relief map of lateral variations for $v_{\mathrm{P}} / v_{\mathrm{S}}$ ratio. The inversion method is the same as that used for the Moho relief map.

observations (Niu et al., 2007). The main purpose of the relief maps is to demonstrate lateral variations of crustal thickness and $v_{\mathrm{P}} / v_{\mathrm{S}}$ ratio across Northeast China. We must note that the maps have no resolution in the corner regions, nor in the tectonic units short of observations, such as the Songliao Basin. The crust is less than 34 $\mathrm{km}$ thick beneath the middle and eastern part of Northeast China, and it gradually thickens towards the North China Block (Figure 3a). The thickest crust occurs beneath the Yanshan fold belt, where the crustal structure could probably be complicated comparing to the rest of regions (Zheng et al., 2007). The apparent dis- 
tinct crustal thickness might be attributed to the multiple phases of contraction and possible occurrence of crustal delamination beneath the Yanshan belt, which is in large contrast to other regions in Northeast China where tectonic extension likely dominated the crustal deformation since the late Mesozoic (e.g., Tian et al., 1992; Davis et al., 2001; Ren et al., 2002; Meng, 2003). The distribution of crustal $v_{\mathrm{P}} / v_{\mathrm{S}}$ ratio has no apparent correlation with the thickness. It presents a low value zone to the northeastern part of our study area, while a high value zone beneath the Changbaishan (Figure $3 \mathrm{~b}$ ). This relatively high $v_{\mathrm{P}} / v_{\mathrm{S}}$ ratio (above 1.85 ) very likely related to the back-arc volcanic activities in the Changbaishan (Lei and Zhao, 2005).

\section{Lateral heterogeneity beneath stations CN2, MDJ and MIH}

While estimating the crustal thickness and $v_{\mathrm{P}} / v_{\mathrm{S}}$ ratio of Northeast China, we found interesting phenomena beneath stations CN2, MDJ and MIH that reveal strong lateral heterogeneous structure along the Suolon suture. Especially on $\mathrm{CN} 2$ and $\mathrm{MIH}$, the crustal lateral heterogeneity is so strong that we could not find an optimal crustal thickness and $v_{\mathrm{P}} / v_{\mathrm{S}}$ ratio by reconciling receiver functions from all back azimuthal directions. The measurements of these two stations are thus the results of a subset of teleseismic events in the direction of northeast $\left(30^{\circ}-60^{\circ}\right.$ in back azimuth) since what they generate estimates well agree with nearby stations. The advanced $H-\kappa$ domain search method sufficiently gives accurate measurements if the crust is of minor lateral heterogeneities. In the case of strong lateral heterogeneities in the crust, the arrivals of P-to-S conversion and crustal multiples are not only the functions of epicentral distances, but also depend on back azimuths. It thus prevents us from reconciling the phases of observed P-to-S conversion and crustal multiples from all back azimuths to the predicted arrivals calculated on homogenous model in $H-\kappa$ domain search.

In order to examine azimuthal dependence of crustal structure around CN2, MDJ and MIH, we binned receiver functions in $30^{\circ}$ back azimuth windows and moved the window at step of 10 . The receiver functions gathered at all back azimuthal bins were applied in our advanced $H-\kappa$ domain search method and mapped to depth profile (Figure 4). All three stations present noticeable variation in Moho depth with back azimuths. However, we also note the fact that although our data sets have all back-azimuthal coverage, more than half of seismicity occurs in the directions of the southeast and southwest given the geographical location of Northeast China. Therefore, the results derived from back azimuths between $110^{\circ}$ and $250^{\circ}$ have higher resolution than from other back azimuth ranges. At CN2 (Figure $4 \mathrm{a})$, the Moho is found at depth of $29 \mathrm{~km}$ from back azimuths $20^{\circ}$ to $50^{\circ}$, and it turns to increase with back
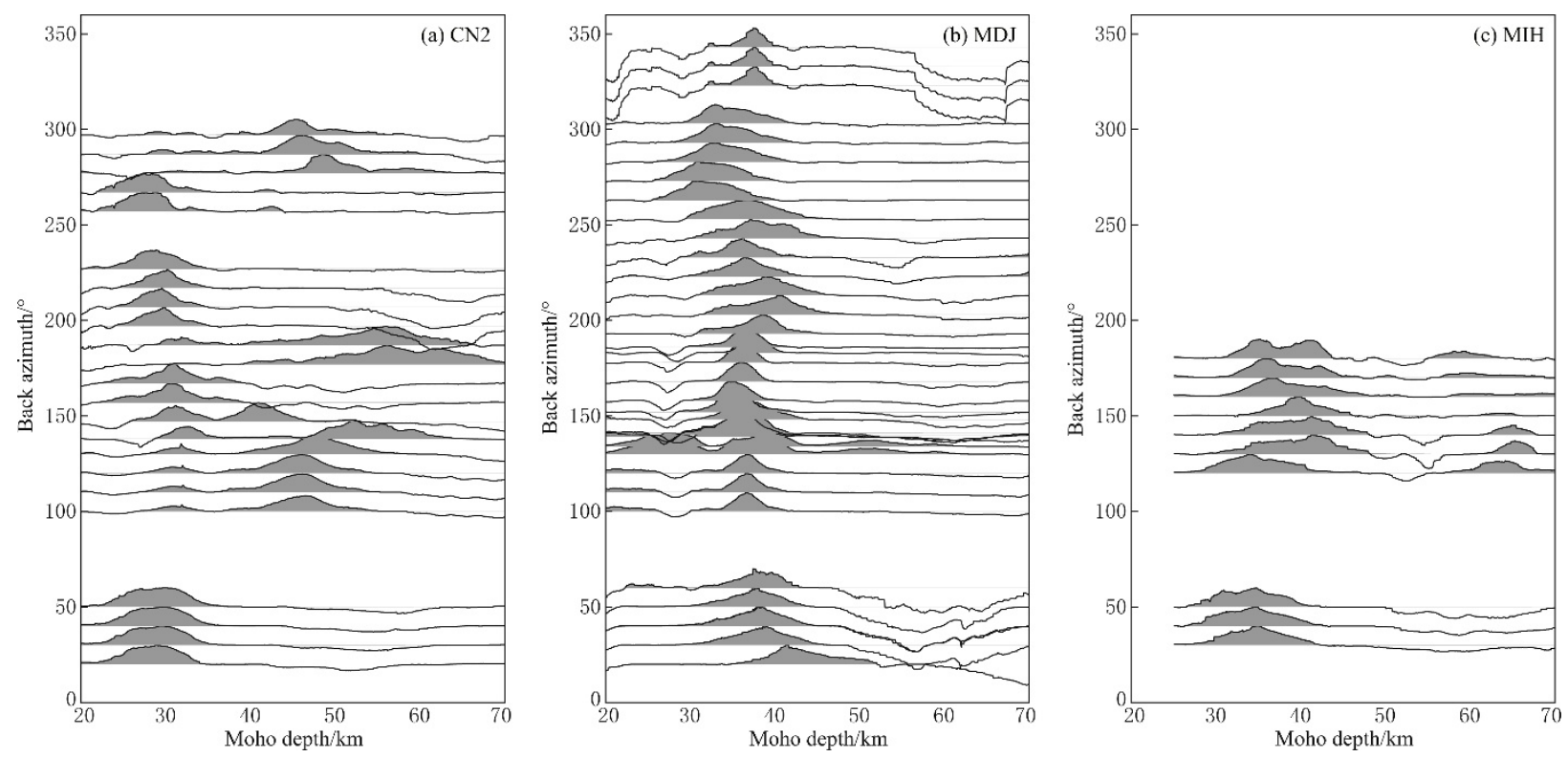

Figure 4 Depth stacked receiver functions generated at back-azimuth bins for stations CN2 (a), MDJ (b), and MIH (c), respectively. 
azimuths. At $100^{\circ}$ to $150^{\circ}$, the Moho depth reaches its maximum, and shows two peaks with different amplitudes in the stacked receiver functions. We adopted a multi-step receiver function modeling method including multiple constraints from grid search, $H-\kappa$ domain search, and $\mathrm{Pn}$ and $\mathrm{Sn}$ wave velocities from previous tomography models to invert for 1 -D shear-wave velocity model beneath CN2 (refer Tkalčić et al. (2010) for details). The final model is simplified from the inversion by combining the layers with small velocity differences (Figure 5a). The model displays a low velocity zone in the middle crust at about $25 \mathrm{~km}$ following by gradually increasing of velocity down to about 38 $\mathrm{km}$. A relatively sharp velocity jump occurs at depth of about $47 \mathrm{~km}$. The velocity model well supports our observation in the depth mapping of receiver functions. Our model suggests very complicated structure of crustmantle transition zone ranging over $10 \mathrm{~km}$ from $30 \mathrm{~km}$ to $47 \mathrm{~km}$ in depth.

From about $150^{\circ}$ to $250^{\circ}$, the back-azimuthal dependence of Moho on station MDJ (Figure 4b) mani- fests an apparent variation in depth. The crust reaches its deepest value of about $41 \mathrm{~km}$ at $200^{\circ}$. A number of controversial estimates of crustal thickness near MDJ indicated the complexity of local structure from different techniques and data sets. For instance, the Moho depth varies from $27 \mathrm{~km}$ from regional $\mathrm{P}$ and $\mathrm{PP}$ waveform modeling (Beckers et al., 1994), 34-36 km by active source seismic refraction experiment (Yuan et al., 1986), 42-43 km by surface wave modeling (Feng et al., 1981), to $36-42 \mathrm{~km}$ by very few receiver functions measurements (Mangino et al., 1999; Ma and Zhou, 2007). The $H-\kappa$ domain search in this study gives an average thickness of $37.5 \mathrm{~km}$. The shear-wave velocity model inverted from receiver functions (Figure 5b) might partly explain the difference between these results. The model also has a low velocity zone in the lower crust. The crustmantle transition zone occurs between about $30 \mathrm{~km}$ and $43 \mathrm{~km}$ with gradually increased velocity. Another apparent velocity jump occurs at depth of about $51 \mathrm{~km}$ in upper mantle as gradually increased zone. The crustal velocity model for station $\mathrm{MIH}$ is similar to $\mathrm{CN} 2$ and
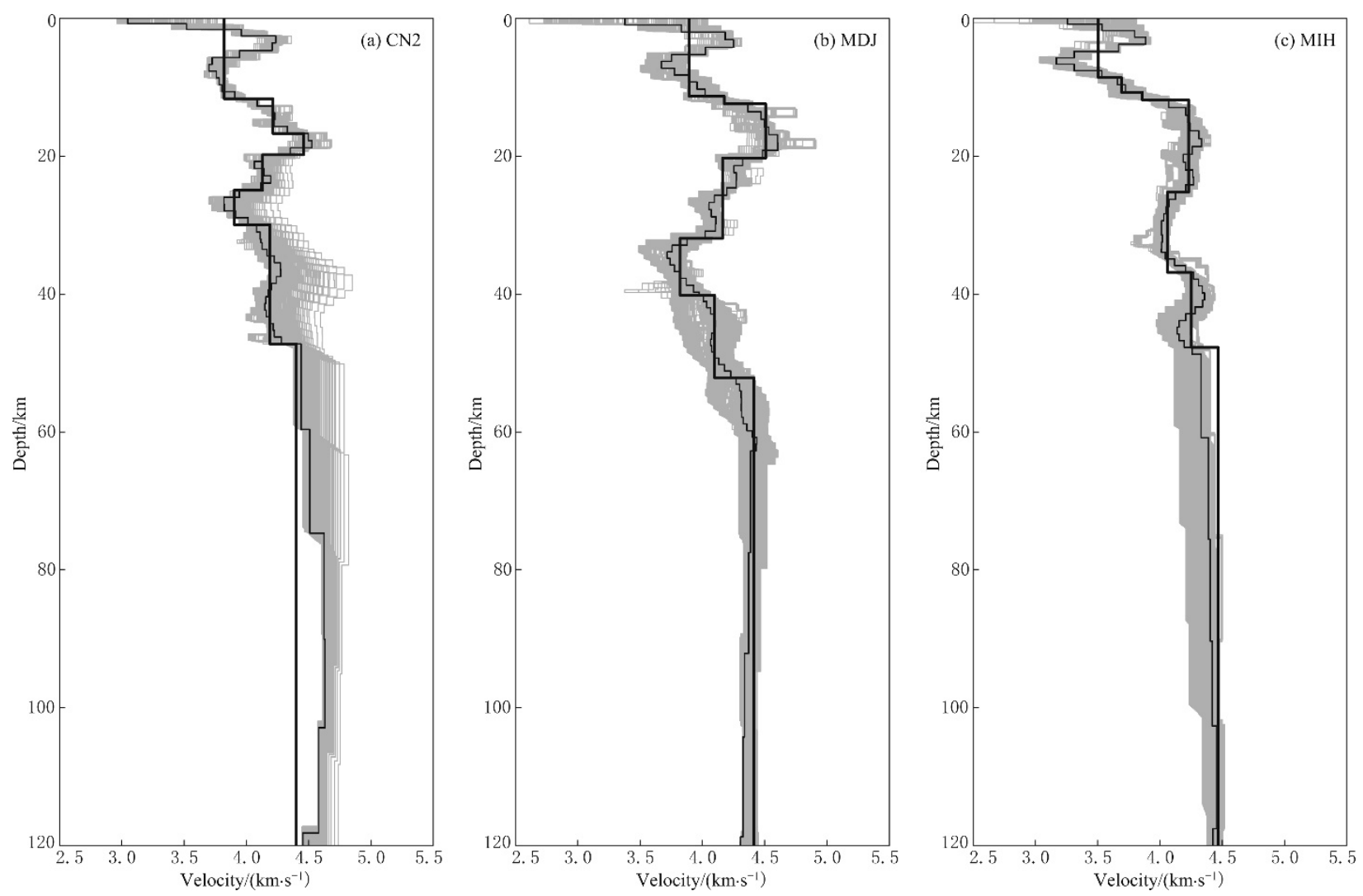

Figure 5 Shear-wave velocity models obtained from linearized inversion of receiver functions for stations CN2 (a), MDJ (b), and MIH (c), respectively. The best fitting models are shown in thin black lines. All iterations with different smoothness weight are shown in gray. The thick black lines indicate simplified models obtained from best fitting models by combining layers with similar velocity values. 
MDJ, but with noticeable difference. Due to relative less number of teleseismic waveforms collected for MIH, we did not have enough observations to conduct $H-\kappa$ domain search for back azimuths above $200^{\circ}$. The available back-azimuthal observations show the variation in Moho depth from $120^{\circ}$ to $230^{\circ}$ (Figure 4c), and the crust-mantle transition zone probably occurs from about $34 \mathrm{~km}$ to about $41 \mathrm{~km}$, which is also revealed in the velocity model (Figure 5c). Comparing to CN2 and MDJ, our receiver function modeling of MIH indicates that it might not have low velocity zone in the middle/lower crust, but might have a low velocity zone in upper mantle.

\section{A hypothesis of lateral hetero- geneity: Dipping interfaces in the crust}

We further investigate the lateral heterogeneity beneath the three stations by checking their tangential receiver functions. The tangential receiver function is complete zero when teleseismic $\mathrm{P}$-wave propagates through an ideal lateral homogenous medium. However, if the tangential receiver function is comparable in amplitude to the radial receiver function, it indicates strong lateral heterogeneity beneath the site. One possibility of lateral heterogeneity is a dipping planar velocity interface, in which both the radial and tangential receiver functions vary with back azimuth in a predictable pattern (e.g., Langston, 1977; Cassidy, 1992; Zhu et al., 1995; Frederikson and Bostock, 2000). The numerical simulation for a model with dipping layers illustrates that the incident $\mathrm{P}$-wave traveling towards the up-dip direction generates the largest and latest arrival of P-to$\mathrm{S}$ phase on the radial receiver function, while the wave traveling towards the down-dip direction generates the smallest and earliest arrival of P-to-S phase. The radial receiver functions are thus symmetric across a line parallel to the dip direction. The tangential receiver functions are anti-symmetric about this direction and have zero amplitude, and the largest amplitudes of arrivals occur on the strike direction of the dipping interface.

For each of these three stations, we grouped and stacked both radial and tangential receiver functions in back azimuth range of $10^{\circ}$, and then aligned and plotted stacked waveforms according to the central values of all back-azimuth ranges (Figures 6-8). Since a lowpass Gaussian filter $(a=1.0)$ was used to generate receiver functions, the arrivals of P-to-S converted phase and crustal multiples as functions of epicentral distances did not cause important move-out in the stacking. At CN2, we found that the largest and latest $\mathrm{P}$-to-S phase arrived at back azimuth $170^{\circ}$ on the radial receiver function, while the tangential receiver function has minimum amplitude on this direction. This direction can be assumed as the down-dip of interface in the crust. At MDJ and $\mathrm{MIH}$, we determined the down-dip direction at $170^{\circ}$ and $190^{\circ}$ respectively.

We calculated synthetics using an anisotropic ray theory code developed by Frederikson and Bostock (2000). The Earth models were taken from the simplified receiver function models shown in Figure 5 for these three stations, plus a crustal dip interface with strike at $80^{\circ}, 80^{\circ}$ and $100^{\circ}$ for $\mathrm{CN} 2$, MDJ and $\mathrm{MIH}$
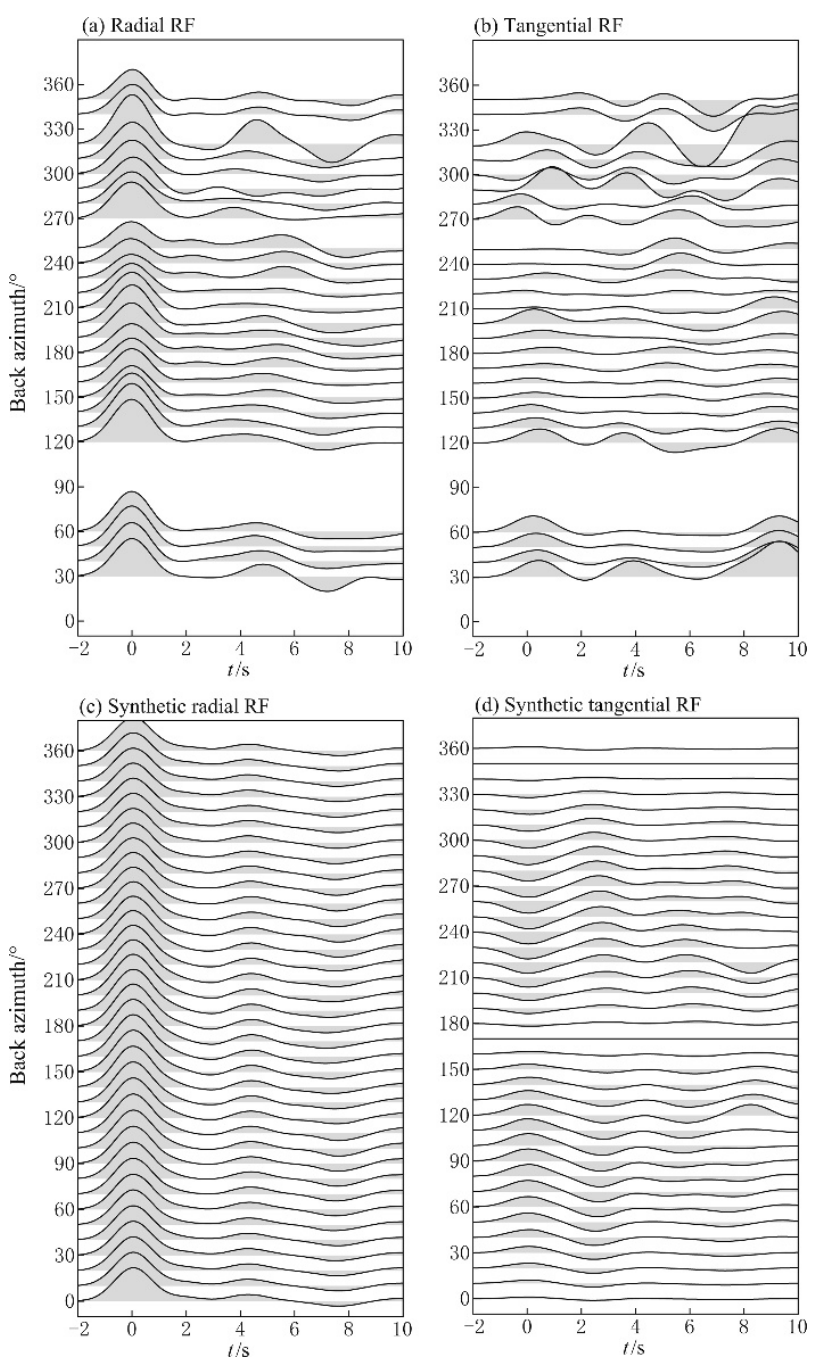

Figure 6 The radial (a) and tangential (b) receiver functions at station CN2 stacked and aligned according to back azimuth. (c) and (d) are synthetic radial and tangential receiver functions at this station. 

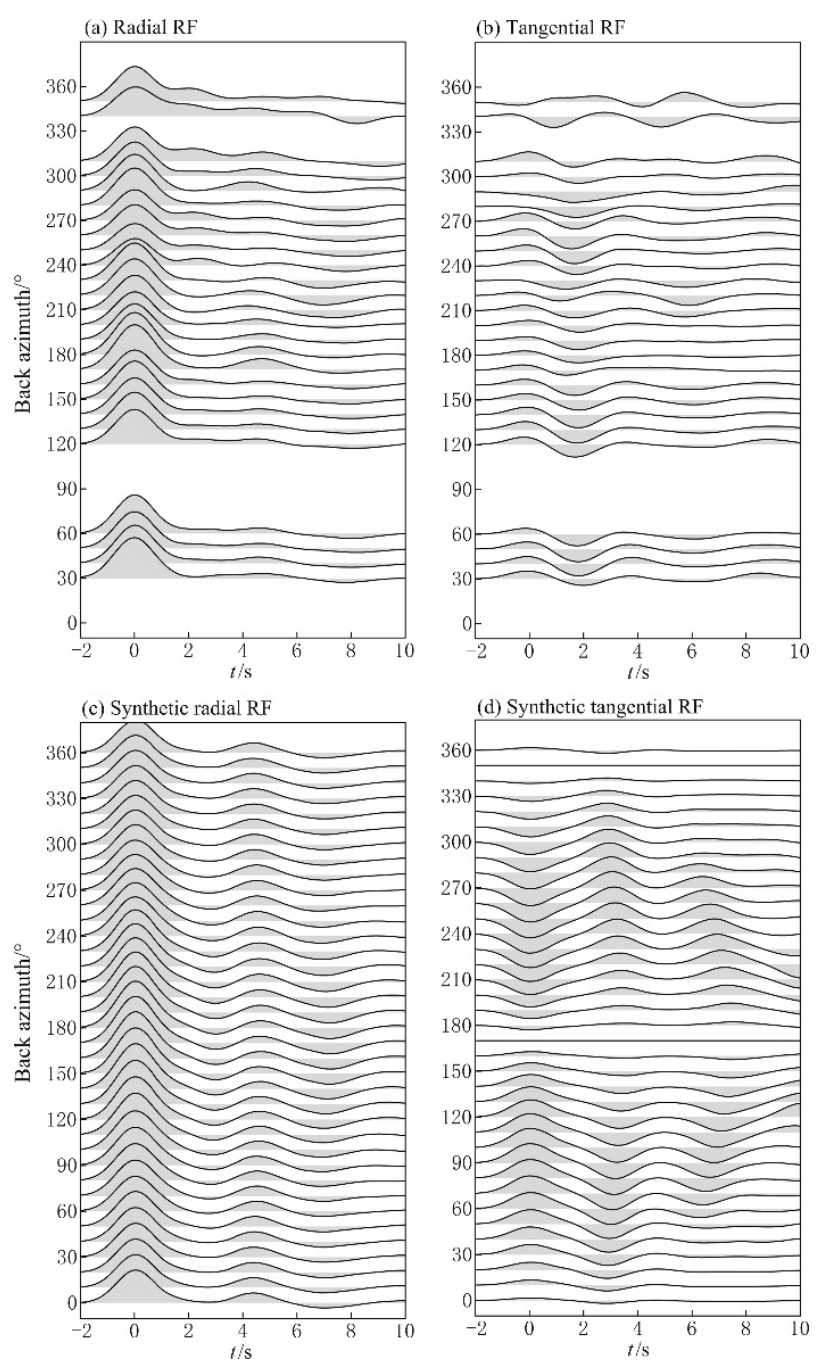

Figure 7 The radial (a) and tangential (b) receiver functions at station MDJ stacked and aligned according to back azimuth. (c) and (d) are synthetic radial and tangential receiver functions at this station.

respectively, and uniform dip angle at $30^{\circ}$. Synthetic receiver functions are plotted in Figures 6-8 to compare with observations on these three stations. In general, the pattern of the arrivals of P-to-S phase varying with bach-azimuth revealed in synthetics is roughly consistent with observed data. The tangential receiver function stacks did not present apparent anti-symmetry as shown in synthetics probably because tangential waveforms are noisier than radial waveforms, as well as large epicentral distances stacking.

\section{Discussion and conclusions}

In this paper, we first estimated the crustal thickness and average $v_{\mathrm{P}} / v_{\mathrm{S}}$ ratio for $19 \mathrm{CNDSN}$ stations
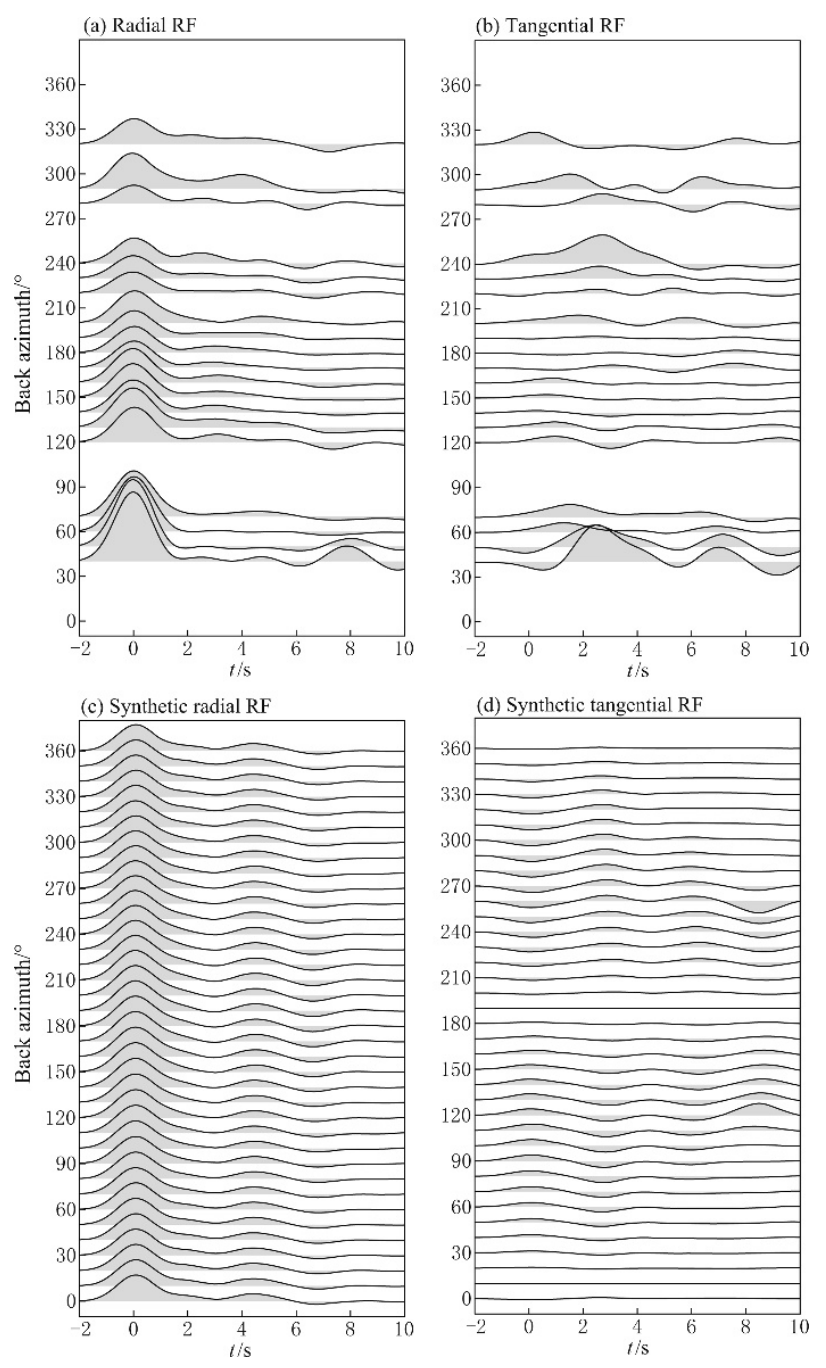

Figure 8 The radial (a) and tangential (b) receiver functions at station MIH stacked and aligned according to back azimuth. (c) and (d) are synthetic radial and tangential receiver functions at this station.

in Northeast China, and then studied crustal lateral heterogeneous structure beneath stations CN2, MDJ and MIH along the Suolon suture. The average crustal thickness of Northeast China is about $34.4 \mathrm{~km}$ with a variation of $10 \mathrm{~km}$ across the entire region. The central part of the study region has thinner crust than the average value, probably associated with the widespread extensional Mesozoic deformation in Northeast China (Cope and Graham, 2007). The thickest crust is found beneath the Sino-Korean Craton, which could be the result of contraction and possible crustal delamination of the Yanshan belt (Meng, 2003). The average crustal $v_{\mathrm{P}} / v_{\mathrm{S}}$ ratio is about $1.733(\sigma=0.251)$, lower than the global average of 1.78 for the bulk continental crust 
(Zandt and Ammon, 1995). The only region with high $v_{\mathrm{P}} / v_{\mathrm{S}}$ ratio (above 1.85) is beneath the Changbai volcano. However, it is difficult to relate the variations in crustal thickness and $v_{\mathrm{P}} / v_{\mathrm{S}}$ ratio with the difference of tectonic blocks in Northeast China from basins and Cratons to fold belts and uplifts based on the results of only 19 stations.

As one of the oldest collision zones in the Asian tectonic collage, the Suolon suture is a $\sim 3000 \mathrm{~km}$ long boundary between Paleozoic arc and accretionary complexes of southern Mongolia and Precambrian microcontinental blocks to the south (Sengor et al., 1993). It welded the Mongolian arc terranes and the Sino-Korean Craton together during the late Permian and early Triassic, and underwent reactivation during the Jurassic and Cretaceous as the Yanshan fold and thrust belt associated with the extension that formed the Hailar Basin and the Songliao Basin in the Mongolian arc terranes (Davis et al., 2001; Graham et al., 2001). The complicated tectonic history, as well as the existence of several known and inferred faults near stations, makes possible the existing of strong lateral heterogeneity in the crust of this region. We found the Moho depth beneath three stations, CN2, MDJ and MIH, along the Suolon suture strongly depend on back azimuth. On the other hand, we did find back-azimuth dependence for another station near the Suolon suture, CIF, which has a normal and flat Moho. This is probably because CIF is located on the Sino-Korean Craton, and the beneath crustal structure is largely dominated by the contraction of the Yanshan belt, instead of tectonic extension of Northeast China (Zheng et al., 2007). CN2, MDJ and $\mathrm{MIH}$ are all located at the most northeastern end of the Suolon suture. The strike runs from about $20^{\circ}$ to about $80^{\circ}$ from the northeast to the west in the region of Northeast China (Figure 1). The back-azimuthal dependent measurements for Moho depth on CN2, MDJ and $\mathrm{MIH}$ indicated the deepest Moho at $180^{\circ}, 200^{\circ}$ and $140^{\circ}$, respectively. If the model of dipping interfaces in the crust is able to explain the observed lateral heterogeneity, the dipping direction must concentrate on the direction roughly perpendicular to the Suolon suture, very likely towards the south or southeast side of the Suolon suture under the Changbaishan.

The preliminary results discussed in this paper mainly focus on the discovery of the strong lateral heterogeneous structure in the crust along the Suolon suture. The dipping interface in the crust might not be the only model to explain the observations because we also note the large dissimilarity between synthetic and observed waveforms (Figures 6-8). The modeling of lateral heterogeneity or dipping interface structure in details involves the determination of many parameters, such as geometry of the dipping interface, possible anisotropy on the interface, as well as a priori knowledge of the Suolon suture. In the future studies for this problem, we will quantitatively determine these parameters in order to improve the waveforms match. Moreover, with more regional seismic stations available and more seismograms accumulated, we will achieve more clear image of crustal and upper mantle structure in this region.

Acknowledgements We thank the stuffs from the China Earthquake Networks Center for providing and processing seismic data. We greatly appreciate Y. Sun and N. Toksöz from MIT for providing the crustal and upper mantle velocity model for China from their tomographic studies. We also thank the Associate Editor and two anonymous reviewers for their constructive reviews that improved the manuscript significantly.

\section{References}

Ammon C J (1991). The isolation of receiver effects from teleseismic P-waveforms. Bull Seismol Soc Am 81: 2 5042510 .

Bassin C, Laske G and Masters G (2000). The current limits of resolution for surface wave tomography in North America. Eos Trans AGU 81: F897, http://igppweb. ucsd.edu/gabi/crust2.html.

Beckers J, Schwartz S Y and Lay T (1994). The velocity structure of the crust and upper mantle under China from broadband P and PP waveform analysis. Geophys $J$ Int 119: 574-594.

Cassidy J F (1992). Numerical experiments in broadband receiver function analysis. Bull Seismol Soc Am 82: 14531474 .

Chen Y, Niu F, Liu R, Huang Z, Tkalčić H, Sun L and Chan W (2010). Crustal structure beneath China from receiver function analysis. J Geophys Res 115: B03307, doi:10.1029/2009JB006386.

Cui Z, Li Q, Wu C, Yin Z and Liu H (1995). The crustal and deep structures in Golmud-Ejin Qi GGT. Acta Geophys Sin 38: 15-28.

Cope T D and Graham S A (2007). Upper crustal response to Mesozoic tectonism in western Liaoning, North China, and implications for lithospheric delamination. Geological Society London Special Publications 280: 201-222.

Davis G A, Zheng Y, Wang C, Darby B J, Zhang C and Gehrels G (2001). Mesozoic tectonic evolution of the Yanshan fold and thrust belt, with emphasis on Hebei and Liaoning provinces, northern China. Geolog Soc America Memoir 194: 171-197. 
Feng R, Zhu J and Ding Y (1981). A study on the crustal structure of China with surface waves. Acta Seismol Sin 3(4): 335-350 (in Chinese).

Frederikson A W and Bostock M G (2000). Modeling teleseismic waves in dipping anisotropic structures. Geophys J Int 141: 401-412.

Graham S A, Hendrix M S, Johnson C L, Badamgarav D, Badarch G, Amory J, Porter M, Barshold M, Webb L E and Hacker B R (2001). Sedimentary record and tectonic implications of Mesozoic rifting in Southeast Mongolia. Geol Soc Am Bull 113: 1560-1579.

Huang Z, Su W, Peng Y, Zheng Y and Li H (2003). Rayleigh wave tomography of China and adjacent regions. J Geophys Res 108(B2): 2 073, doi:10.1029/2001JB001696.

Langston C A (1977). The effect of planar dipping structure on source and receiver responses for constant ray parameter. Bull Seismol Soc Am 67: 1029-1 050.

Langston C A (1979). Structure under Mount Rainier, Washington, inferred from teleseismic body waves. J Geophys Res 84: 4749-4 762.

Lei J and Zhao D (2005). P-wave tomography and origin of the Changbai intraplate volcano in Northeast Asia. Tectonophysics 397: 281-295.

Li S L and Mooney W D (1998). Crustal structure of China from deep seismic sounding profiles. Tectonophysics 288: 105-113.

Li S L, Mooney W D and Fan J (2006). Crustal structures of mainland China from deep seismic sounding data. Tectonophysics 420: 239-252.

Liang C, Song X and Huang J (2004). Tomographic inversion of $\mathrm{Pn}$ travel times in China. $J$ Geophys Res 109: B11304, doi:10.1029/2003JB002789.

Liu M, Mooney W D, Li S, Okaya N and Detweiler S (2006). Crustal structure of the northeastern margin of the Tibetan plateau from the Songpan-Ganzi terrane to the Ordos basin. Tectonophysics 420: 253-266.

Ma Y and Zhou H (2007). Crustal thickness and Poisson's ratios in China by joint analysis of teleseismic receiver function and Rayleigh wave dispersion. Geophys Res Lett 34: L12304, doi:10.1029/2007GL029848.

Mangino S, K Priestley and Ebel J (1999). The receiver structure beneath the China digital seismograph network stations. Bull Seismol Soc Am 89: 1053-1076.

Meng Q R (2003). What drove late Mesozoic externsion of the northern China-Mongolia tract? Tectonophysics 369: $155-174$.

Nair S K, Gao S S, Liu K H and Silver P G (2006). Southern African crustal evolution and composition: Constraints from receiver function studies. J Geophys Res 111: B02304, doi:10.1029/2005JB003802.

Niu F, Bravo T, Pavlis G, Vernon F, Rendon H, Bezada $M$ and Levander A (2007). Receiver function study of the crustal structure of the southeastern Caribbean plate boundary and Venezuela. J Geophys Res 112,
doi:10.1029/2006JB004802.

Pei S, Xu Z and Wang S (2004). Sn wave tomography of the uppermost mantle beneath the China continent and adjacent regions. Chinese J Geophys 47: 278-284.

Ren J Y, Tamaki K, Li S T and Zhang J X (2002). Late Mesozoic and Cenozoic rifting and its dynamic setting in Eastern China and adjacent areas. Tectonophysics 344: 175-205.

Sengor A M C, Natal'in B A and Burtman V S (1993). Evolution of the Altaid tectonic collage and Palaeozoic crustal growth in Eurasia. Nature 364: 299-307.

Sun Y and Toksöz M N (2006). Crustal structure of China and surrounding regions from $\mathrm{P}$ wave traveltime tomography. J Geophys Res 111: B03310, doi: 10.1029/2005JB003962.

Sun Y, Toksöz M N, Pei S and Morgan F D (2008). The layered shear-wave velocity structure of the crust and upper mantle in China. Bull Seismol Soc Am 98: 746-755, doi:10.1785/0120050222.

Sun Y S, Li X, Kuleli S, Morgan F D and Toksöz M N (2004). Adaptive moving window method for 3-D P-velocity tomography and its application in China. Bull Seismol Soc Am 94: 740-746.

Tian Z, Han P and Xu K (1992). The Mesozoic-Cenozoic east China rift system. Tectonophysics 208: 341-363.

Tkalčić H, Chen Y, Liu R, Huang Z, Li S and Chan W (2010). Multi-step modeling of teleseismic receiver functions combined with constraints from seismic tomography: crustal structure beneath southeastern China. submitted to GJI.

Vergne J, Wittlinger G, Hui Q, Tapponnier P, Poupinet G, Mei J, Herquel G and Paul A (2002). Seismic evidence for stepwise thickening of the crust across the NE Tibetan plateau. Earth Planet Sci Lett 203: 25-53.

Vermeesch P (2003). A second look at the geologic map of China: The "sloss approach". Intern Geol Rev 45: 119132.

Wang C Y, Han W B, Wu J P, Lou H and Chan W W (2007). Crustal structure beneath the eastern margin of the Tibetan Plateau and its tectonic implications. $J$ Geophys Res 112: B07307, doi:10.1029/2005JB003873.

Wang C Y, Zeng R S, Mooney W D and Hacker B R (2000). A crustal model of the ultrahigh-pressure Dabie Shan orogenic belt, China, derived from deep seismic refraction profiling. J Geophys Res 105(B5): $10857-10869$.

Wang Y, Mooney W D, Yuan X and Coleman R G (2003). The crustal structure from the Altai Mountains to the Altyn Tagh fault, northwest China. J Geophys Res 108(B6): 2322, doi:10.1029/2001JB000552.

Yin A and Nie S Y (1996). A Phanerozoic palinspastic reconstruction of China and its neighboring regions. In: Yin A and Harrison T M eds. The Tectonic Evolution of Asia. Cambridge University Press, NY, 442-485.

Yuan X, Wang S, Li L and Zhu J (1986). A geophysical inves- 
tigation of the deep structure in China. In: Barazangi M and Brown L eds. Reflection Seismology: A Global Perspective (Geodynamic Series). AGU, Washington DC, 13: $151-160$.

Zandt G and Ammon C J (1995). Continental crust composition constrained by measurements of crustal Poisson's ratio. Nature 374: 152-154.

Zhang Z, Badal J, Li Y, Chen Y, Yang L and Teng J (2005). Crust-upper mantle seismic velocity structure across Southeastern China. Tectonophysics 395: 137157.

Zhao J, Mooney W D, Zhang X, Li Z, Jin Z and Okaya N (2006). Crustal structure across the Altyn Tagh Range at the northern margin of the Tibetan plateau and tec- tonic implications. Earth Planet Sci Lett 241: 804-814. Zheng S, Sun X, Song X, Yang Y and Ritzwoller M H (2008). Surface wave tomography of China from ambient seismic noise correction. Geochem Geophys Geosyst 9: Q05020, doi: 10.1029/2008GC001981.

Zheng T, Chen L, Zhao L and Zhu R (2007). Crustal structure across the Yanshan belt at the northern margin of the North China Craton. Phys Earth Planet Inter 161: $36-49$.

Zhu L, Owens T J and Randall G E (1995). Lateral variation in crustal structure of the Northern Tibetan Plateau inferred from teleseismic receiver functions. Bull Seismol Soc Am 85: 1531-1540. 